\title{
Solution Behaviour of Ternary Complexes of Cobalt (II) Involving Sulfanilamide and Dicarboxylic acids
}

\author{
Eida S. Al-Farraj ${ }^{1}$, Murefah M. Anazy ${ }^{2}$, Amani S. Alturiqi ${ }^{2}$, and Reda A. Ammar ${ }^{3, *}$ \\ ${ }^{1}$ Department of Chemistry, College of Science, Imam Mohammad Ibn Saud Islamic University \\ (IMSIU), 13623, Riyadh, Saudi Arabia \\ ${ }^{2}$ Department of Chemistry, College of Science, Princess Nourah bint Abdulrahman University, \\ Riyadh, Saudi Arabia \\ ${ }^{3}$ Department of Chemistry, College of Science, Al Azhar University, Cairo, Egypt \\ *E-mail: $\underline{\text { dr_reda06@yahoo.com }}$
}

doi: $10.20964 / 2021.01 .26$

Received: 19 September 2020 / Accepted: 4 November 2020 / Published: 30 November 2020

\begin{abstract}
Stability constants and complex formation equilibria between $\mathrm{Co}(\mathrm{II})$ and sulfanilamide (SM) with dicarboxylic acids (L) were studied $\mathrm{pH}$-metrically at $25 \pm 0.1^{\circ} \mathrm{C}$ and ionic strength $I=0.1 \mathrm{~mol} / \mathrm{L} \mathrm{NaClO}_{4}$ in aqueous solutions. The stepwise method is responsible for the formation of [Co(II)-SM-L] complexes, while dicarboxylic acid ligation follows sulphanilamide-Co(II) binding. Stability constants were obtained by applying the potentiometric data in HYPERQUAD computer program. The stoichiometry of the formed complexes was confirmed by conductometric method. A comparison between binary and ternary complexes' relative stabilities was conducted.
\end{abstract}

Keywords: Stability constant, Co(II), Sulfanilamide, Dicarboxylic acids, pH-metrically.

\section{$\underline{\text { FULL TEXT }}$}

(C) 2021 The Authors. Published by ESG (www.electrochemsci.org). This article is an open access article distributed under the terms and conditions of the Creative Commons Attribution license (http://creativecommons.org/licenses/by/4.0/). 